\title{
Update on the usage and safety of epinephrine auto-injectors, 2017
}

\author{
This article was published in the following Dove Press journal: \\ Drug, Healthcare and Patient Safety \\ 21 March 2017 \\ Number of times this article has been viewed
}

\author{
Larry S Posner' \\ Carlos A Camargo Jr ${ }^{2}$ \\ 'North Bay Allergy and Asthma \\ Associates, Inc., Napa, CA, \\ ${ }^{2}$ Department of Emergency Medicine, \\ Massachusetts General Hospital, \\ Harvard Medical School, Boston, \\ MA, USA
}

\begin{abstract}
Anaphylaxis is a serious, potentially fatal allergic reaction. Guidelines recommend prompt intramuscular injections of epinephrine as the first-line therapy for anaphylaxis. Delayed epinephrine treatment may cause undesirable clinical outcomes, including death. In the community, epinephrine auto-injectors (EAIs) are commonly used to treat anaphylaxis. This literature review examines several recent concerns regarding the safety of EAIs that may prevent the timely administration of epinephrine. Reports of cardiovascular complications are linked with epinephrine administration, although recent studies suggest that these events are much more commonly associated with intravenous epinephrine rather than with EAIs. Recent studies have also highlighted accidental injections of EAIs in patients' or caregivers' fingers and lacerations associated with the use of EAI in children. However, the data suggest that both accidental injections and lacerations are rare and require limited medical intervention. In addition, patients may receive conflicting information on the safety and efficacy of using expired EAIs. Overall, it is believed that the benefits of using EAIs far outweigh the potential risks of not administering an EAI. Although legitimate safety concerns are associated with EAIs, adverse events are rare. Continued training of medical providers, caregivers, and patients may be beneficial to address these concerns and reduce EAI-associated injuries while ensuring that patients receive necessary medical care.
\end{abstract}

Keywords: allergy, anaphylaxis, asthma, pediatrics

\section{Background}

Anaphylaxis is a severe, acute, and potentially fatal allergic reaction that can develop within minutes of exposure to an immunologic trigger. ${ }^{1,2}$ Major medical groups recommend prompt intramuscular (IM) injection of epinephrine as the first-line therapy for anaphylaxis..$^{2-5}$ Epinephrine auto-injectors (EAIs) can be used in the community for prompt delivery of epinephrine, ${ }^{2}$ which is known to significantly improve outcomes in individuals experiencing anaphylaxis..$^{6-8}$ Despite the potentially life-saving benefits of using EAIs, epinephrine is not used to treat the majority of anaphylactic reactions. ${ }^{9}$ There are several reasons why EAIs are not administered, including lack of availability and concerns over safety. ${ }^{9}$ Many parents have reservations about potentially using an EAI to administer epinephrine to their children due to concerns over injury, incorrect use, and poor outcomes. ${ }^{10}$ Prevalent safety concerns regarding the use of EAIs include cardiovascular (CV) complications, ${ }^{11-13}$ accidental injections, ${ }^{14-16}$ laceration injuries, ${ }^{17,18}$ and the use of expired EAIs. ${ }^{19}$ The present literature review provides an overview of anaphylaxis and discusses the safety concerns, highlighting the recent developments on their frequency, severity, and prevention.
Correspondence: Larry S Posner North Bay Allergy and Asthma Associates, Inc., I 100 Pear Tree Lane, Napa, CA 94558, USA

$\mathrm{Tel}+\mathrm{I} 7072588100$

Fax +I 7072580734

Email LPosnerMD@NorthBayAllergy. com 


\section{Overview of anaphylaxis}

Anaphylaxis is a serious allergic reaction that is rapid in onset and, in rare cases, may cause death. ${ }^{1}$ Many immunologic triggers can induce an anaphylactic reaction, the most common being food, insect venom, and medication. ${ }^{5,20-22}$ The rate of anaphylaxis appears to be increasing dramatically in the developed countries, ${ }^{23,24}$ which may partially be due to an increase in the prevalence of food allergies. ${ }^{25}$ Individuals with a previous history of allergic reactions and asthma are at the greatest risk. ${ }^{7,22}$ However, anaphylaxis can commonly occur in those with no known history of allergy, ${ }^{22}$ and triggers are never identified in many cases. ${ }^{20-22}$ Results from one study on a private allergy practice suggest that more than half of all the cases are idiopathic. ${ }^{26}$ Accordingly, predicting who is at the greatest risk of a fatal reaction has been proven to be very difficult. ${ }^{27}$

Anaphylactic reactions often occur within minutes of exposure to a trigger. ${ }^{2}$ Triggers can induce reactions affecting multiple organs, including the skin, lungs, heart, and gastrointestinal system. ${ }^{2,21}$ Symptoms are diverse, including pruritus, hives, angioedema, breathing difficulties, abdominal pain, tachycardia, hypotension, and, potentially, cardiac arrest. Anaphylaxis is likely when one of three combinations of symptoms is observed (Figure 1). ${ }^{1,2}$ Symptoms affecting the skin are the most common and easy to recognize but might not always be present. ${ }^{2}$ As a wide range of organ systems are affected, the best therapies for anaphylaxis are those that can be used to treat all of the most serious symptoms.

Guidelines from the World Allergy Organization and other major medical groups recommend prompt IM injection of epinephrine as the first-line therapy for anaphylaxis. ${ }^{2-5}$ Epinephrine is a naturally occurring ligand of adrenergic receptors, a broadly expressed class of G-protein-coupled receptors with distinct functions. ${ }^{28}$ Through adrenergic receptor signaling, epinephrine has a variety of physiological effects (Figure 2). 2,29 Epinephrine induces vasoconstriction, increases blood pressure, and decreases mucosal edema through action on the $\alpha_{1}$-adrenergic receptor. Activation of the $\beta_{1}$-adrenergic receptor increases cardiac output, whereas activation of the $\beta_{2}$-adrenergic receptor increases bronchodilation and reduces immune mediator release. Thus, the administration of exogenous epinephrine can counteract some of the most severe symptoms of anaphylaxis.

However, epinephrine may still be used less frequently than other medications for the treatment of anaphylaxis. Although the prehospital use of epinephrine for anaphylaxis is increasing,,$^{30}$ a 2010 multicenter study of emergency departments found that half of the children with food-related anaphylaxis were never treated with epinephrine, and the majority were treated with antihistamines. ${ }^{31}$ Similarly, results from a survey on anaphylaxis survivors treated in a community setting demonstrated that epinephrine was not administered in the majority of cases, and the use of antihistamines was listed as the most common reason for why epinephrine was not administered. ${ }^{9}$ In contrast to epinephrine, antihistamines do not treat some of the most severe symptoms of anaphylaxis. ${ }^{2,29} \mathrm{H}_{1}$-antihistamines (eg, diphenhydramine) can help relieve some of the skin and nasal symptoms of anaphylaxis, whereas $\mathrm{H}_{2}$-antihistamines (eg, ranitidine) may be effective in treating tachycardia and hives. However, antihistamines fail to treat many of the critical CV or pulmonary effects in a sufficiently timely manner. Antihistamines also have a relatively long time to onset of activity $(0.7-3 \mathrm{~h})^{32}$ and time to peak plasma concentration $(0.8-2.8 \mathrm{~h})^{33}$ and as such are not recommended as a first-line therapy for anaphylaxis.

Early use of epinephrine is associated with prevention of hypotension, decreased rates of hospitalization, and increased survival. ${ }^{6-8}$ In the community, epinephrine can be promptly delivered via an EAI. ${ }^{2}$ EAIs can be self-administered or administered by another individual upon onset of symptoms. A report from a Chicago-area hospital suggests that prescriptions for EAIs are increasing, ${ }^{30}$ as patients and providers are realizing the life-saving benefits of EAIs and importance of preparedness. Several brands of EAIs are currently available, with the EpiPen ${ }^{\circledR}$ Auto-Injector devices (Mylan Specialty L.P., Canonsburg, PA, USA) being the most widely prescribed, with a $90 \%$ EAI market share in the US. ${ }^{18,34,35}$ Patients admitted in emergency departments for anaphylaxis were less likely to be hospitalized if they had filled an EAI prescription in the prior year. This suggests that prescribing EAIs may prevent hospitalizations in patients with anaphylactic reactions. ${ }^{36}$ However, predicting who is at a risk of fatal anaphylactic reactions is difficult as the severity of previous reactions is not indicative of the severity of subsequent reactions. ${ }^{27}$ Although epinephrine is an important, potentially life-saving, first-line therapy for anaphylaxis, there are several obstacles that may prevent someone from receiving timely epinephrine.

Major obstacles to prompt the administration of epinephrine in the community setting include both the availability of an EAI and accessibility of someone who has been trained to use an EAI. Results from a 2012 survey of US paramedics indicated that $<40 \%$ of emergency response vehicles stocked EAIs. ${ }^{37}$ In addition, many of these paramedics were unprepared to properly treat anaphylaxis, as $54 \%$ of patients were unable to correctly identify epinephrine as the first-line 


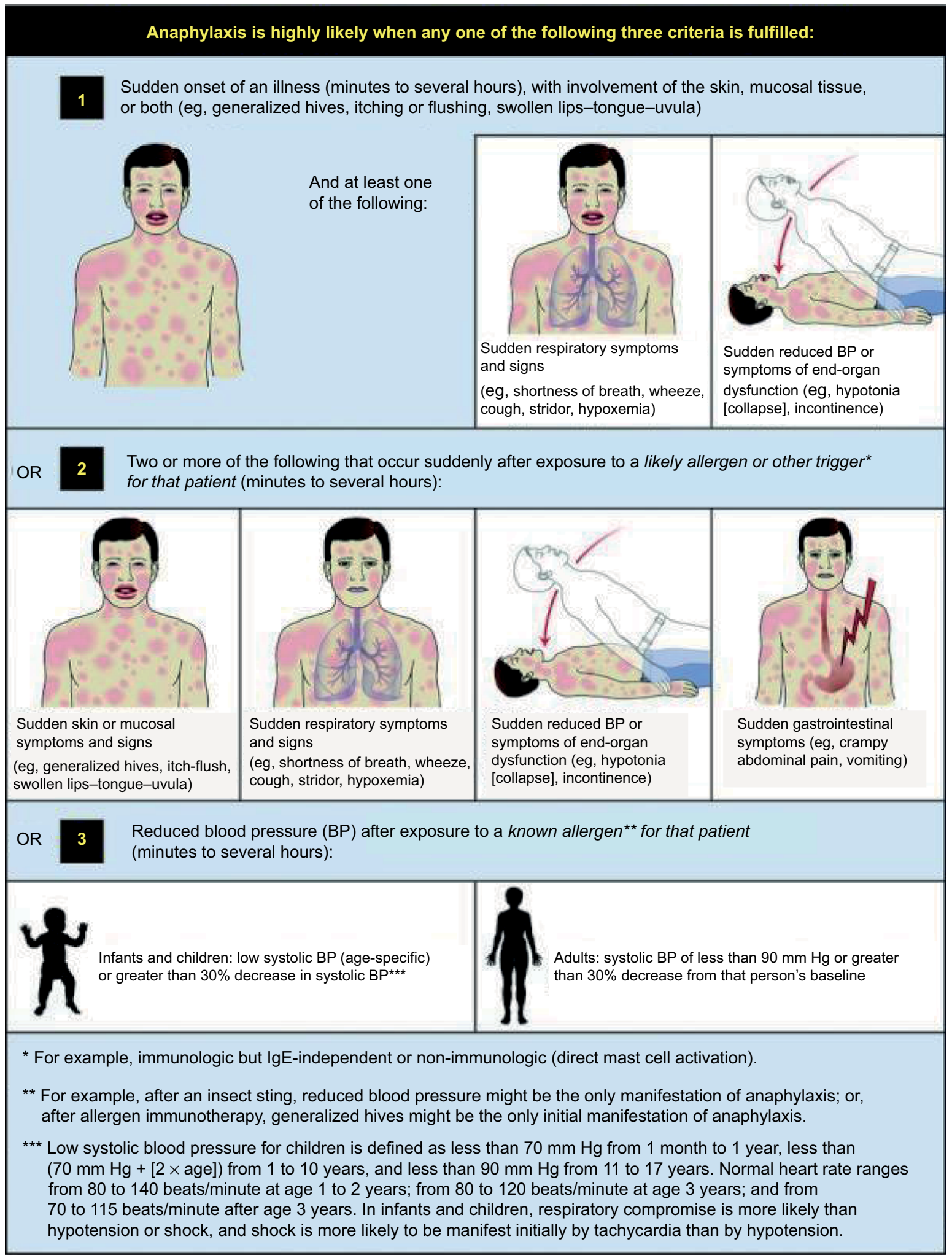

Figure I Criteria that increase the likelihood of anaphylaxis.

Note: Adapted from Simons FE, Ardusso LR, Bilò MB, et al. World allergy organization guidelines for the assessment and management of anaphylaxis. World Allergy Organ J. 201 ।;4(2): 13-37. ${ }^{2}$

drug of choice for anaphylaxis. Similarly, severe allergic reactions can occur on commercial aircraft, sometimes requiring diversion..$^{38}$ Currently, the Federal Aviation Administration (FAA) does not require that airplane emergency medical kits contain epinephrine for the treatment of anaphylaxis, and the FAA recommends the use of oral antihistamines for the treatment of anaphylaxis. ${ }^{39,40}$ Ready availability of EAIs in school settings is also a major public health concern, as 


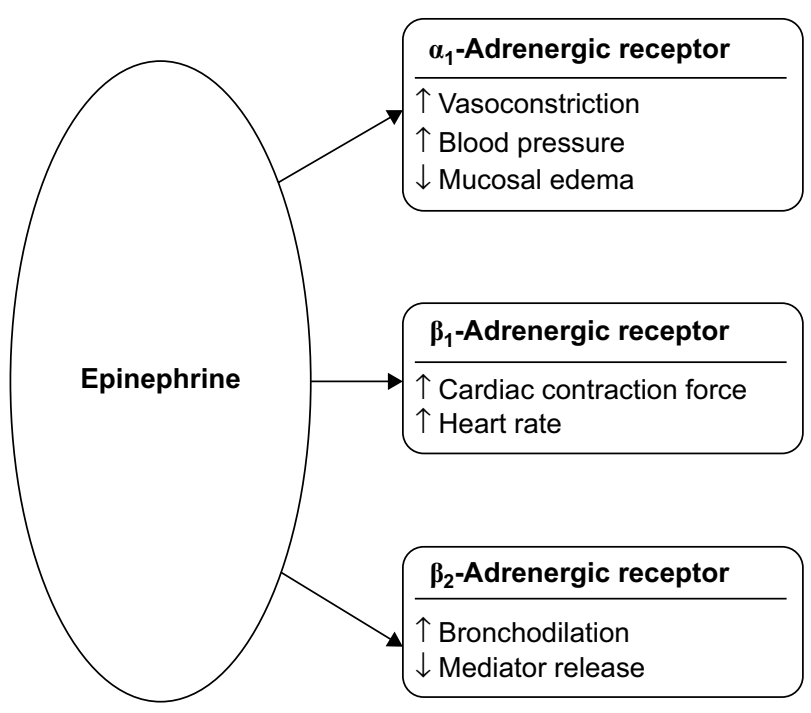

Figure 2 Pharmacological effects of epinephrine in the treatment of anaphylaxis.

the prevalence of food allergies among children is increasing. ${ }^{25}$ Anaphylactic events do occur in schools and have been frequently documented in students with no history of prior allergic reactions. ${ }^{22,41}$ However, some schools may not have stock EAIs available to students. ${ }^{22}$

As accessibility in the community is lacking, important steps have been taken on multiple levels to make life-saving epinephrine more widely available. Currently, the National Association of Emergency Medical Services (EMS) physicians recommends that EMS providers be trained to recognize anaphylaxis and permitted to administer epinephrine in the field. ${ }^{42}$ Recently, the US Senate introduced the Airline Access to Emergency Epinephrine Act, which, if passed, would require airlines to stock EAIs in their emergency medical kits. ${ }^{43}$ Similarly, in 2013, the US Federal Government enacted the School Access to Emergency Epinephrine Act, which provides funding incentives to states that require schools to stock EAIs and to train staff to administer epinephrine. ${ }^{44}$ State- and district-level policies are also being put into place to make stock epinephrine more widely available..$^{45,46}$ In addition, the manufacturer of the EpiPen Auto-Injector, Mylan Specialty L.P., provides free EAIs to schools participating in the EpiPen4Schools ${ }^{\circledR}$ program. ${ }^{22}$ More than 60,000 US public and private schools have participated in this program. Altogether, these legislative changes, policy implementations, and EAI stocking programs are working toward improving the treatment of anaphylaxis in the community and increasing access to EAIs.

However, even if EAIs are available, safety concerns may prevent them from being administered in some situations. Parents still have reservations about using EAIs to administer epinephrine to their children, citing concerns over injury, incorrect use, and poor outcomes. ${ }^{10}$ These can include CV complications, ${ }^{11-13}$ accidental injections, ${ }^{14-16}$ laceration injuries, ${ }^{17,18}$ and the use of expired epinephrine. ${ }^{19}$ The following sections discuss these safety concerns, highlighting the recent developments on their frequency, severity, and prevention.

\section{CV complications}

For decades, there have been reports on epinephrine administration resulting in severe, and sometimes fatal, CV complications. ${ }^{11-13}$ Epinephrine increases cardiac output through action on the $\beta_{1}$-adrenergic receptors in the heart. ${ }^{2}$ In addition, epinephrine induces vasoconstriction through the activation of the $\alpha_{1}$-adrenergic receptor. Due to the combination of vasoconstriction and increased cardiac output, several $\mathrm{CV}$ adverse events (AEs) could potentially occur after the administration of exogenous epinephrine, including myocardial ischemia, ventricular tachycardia, and myocardial infarction. ${ }^{13}$

A recent literature review suggested that the majority of CV AEs seem to occur when epinephrine is administered via the intravenous (IV) route. ${ }^{13}$ These results were subsequently supported by a study on emergency department patients that demonstrated that CV AEs occurred in $10 \%$ of patients with anaphylaxis who received epinephrine as an IV bolus. ${ }^{12}$ In contrast, only $1.3 \%$ of patients presented with CV AEs when epinephrine was administered via IM injection, none of which were considered major. It is notable that the majority of serious CV AEs due to IV administration of epinephrine occurred in adults, ${ }^{12,13}$ suggesting that these events may be less common in children than in adults. Many of these CV complications occur when an excessive dose of epinephrine is administered. ${ }^{12,47}$ Epinephrine overdoses may result from confusion between the IM dose recommended for the treatment of anaphylaxis $(0.3-0.5 \mathrm{mg}$ of $1 \mathrm{mg} / \mathrm{mL}$ concentration $[1: 1,000])$, the IV dose used for the treatment of anaphylactic shock ( $0.1 \mathrm{mg}$ of $0.1 \mathrm{mg} / \mathrm{mL}$ concentration [1:10,000]), and the IV dose used for the treatment of cardiac arrest (1 mg of $0.1 \mathrm{mg} / \mathrm{mL}$ concentration $[1: 10,000]) .{ }^{47}$ When tested, only $61 \%$ of doctors could correctly determine the volume of epinephrine required when the concentration and desired mass were given ${ }^{48}$ demonstrating how simple math miscalculations could result in a fatal dosing error. Results from an informal survey suggested that nearly all hospitals carried prefilled syringes of high dose of epinephrine appropriate for treating cardiac arrest while not carrying prefilled syringes of the dose used for the treatment of anaphylaxis. ${ }^{47}$ In addition, confusion may arise from the use of ratios (eg, 1:1,000), percentages (eg, $0.1 \%$ ), and metric units (eg, $1 \mathrm{mg} / \mathrm{mL}$ ) to express concentrations of various drugs. ${ }^{49}$ In order to help alleviate 
this uncertainty, the US Pharmacopeia and the National Formulary have issued new regulations no longer allowing the use of ratios to express concentrations of single-entity drug products, such as epinephrine. Accordingly, epinephrine concentrations are now to be expressed only in metric units. Although these changes may lead to fewer dosing errors in the long term, there is a concern that they may actually generate more confusion in the short term as providers adjust. ${ }^{49}$ Thus, administration of epinephrine via a stock EAI, containing the correct dose, may help prevent $\mathrm{CV}$ complications resulting from dosing errors associated with IV delivery.

In addition to being recognized as generally safe, IM administration of epinephrine is regarded as an effective therapy for anaphylaxis. ${ }^{2}$ Accordingly, guidelines indicate that IM administration of epinephrine should be used in all settings, except under extreme circumstances. ${ }^{2-5}$ It is even recommended that patients with underlying ischemic heart disease be administered epinephrine to treat an anaphylactic reaction as a decrease in filling pressure due to anaphylaxis can occur and result in the progression of ischemia. ${ }^{50} \mathrm{How}-$ ever, a 2013 survey showed that although $>90 \%$ of pediatric emergency physicians correctly identified epinephrine as the drug of choice for the treatment of anaphylaxis, only two-thirds correctly identified IM injection as the preferred route of administration. ${ }^{51}$ Therefore, even in an emergency setting, there appears to be some lack of awareness of how to properly and safely treat anaphylaxis. The use of clearly labeled stock EAIs ("use only for anaphylaxis") and prefilled syringes ("use only for cardiac arrest") coupled with the circulation of a memo on proper administration of epinephrine has been successful in reducing AEs in a hospital setting. ${ }^{47}$ Thus, simple policy changes and training may help reduce $\mathrm{CV}$ complications and overdoses when using epinephrine to treat anaphylaxis.

\section{Accidental injections}

Accidental injections of EAIs are a known concern that can occur under a variety of circumstances, such as when someone holds an EAI upside down and places his or her thumb on the tip during administration. ${ }^{14-16} \mathrm{~A}$ recent report shows that accidental injections can also occur when a child is playing with an EAI or confuses an actual EAI with a trainer device. ${ }^{52}$ How commonly accidental injections of EAIs occur is unknown, but several reports suggest that the incidence of such events is increasing. ${ }^{53,54}$ In addition, the potential severity of these events has, until recently, been unclear.

As an agonist of the $\alpha_{1}$-adrenergic receptor in vascular smooth muscle, epinephrine induces vasoconstriction. ${ }^{2}$
Through this mechanism, it is possible that accidental digital injection of epinephrine may cause local ischemia and subsequent tissue necrosis. There have been reports of accidental injections resulting in severe vasoconstriction, leading to amputation of a digit. ${ }^{54}$ However, the frequency of digital tissue necrosis and permanent damage from accidental EAI injection has been called into question, as published reports of such events have been notably rare. ${ }^{55}$ A 6-year retrospective study from the Texas Poison Center Network of 365 accidental injections showed that ischemia occurred in only $3.1 \%$ of the cases and completely resolved within $24 \mathrm{~h}$ in all the cases, without any complications (no patients were hospitalized, required surgery, or developed necrosis). ${ }^{56} \mathrm{~A}$ systematic review also indicated that $>99 \%$ of patients with accidental injections made a full recovery. ${ }^{57}$ When necessary, the most frequently administered treatments for those requiring medical intervention included topical administration of nitroglycerin and subcutaneous administration of the $\alpha_{1}$-adrenergic receptor antagonist phentolamine. ${ }^{16,55,56}$

Although the direct effects of accidental EAI injection are not usually serious, the loss of the dose required to treat the anaphylactic attack could be fatal. ${ }^{53}$ Approximately $10 \%$ of accidental injections occurred while administering an EAI to another person. ${ }^{53}$ In these cases, the person experiencing the anaphylactic attack may suffer delayed epinephrine administration. Although the scientific literature fails to provide much insight into the potential significance of the "lost dose hazard", there was a media report of a child dying after a caregiver accidentally injected herself with an EAI. ${ }^{58}$ An EAI 2 pack would allow for multiple doses to be on hand, ${ }^{59,60}$ which may help offset lost dose concerns.

The best way to alleviate safety concerns associated with accidental injection of EAIs is to ensure proper administration. Appropriate technique dictates that an EAI be held in the palm with the thumb covering the index finger (Figure 3) ${ }^{60,61}$ If the thumb is placed on a tip, an accidental injection could occur, especially if the device is being held upside down. Patients and caregivers may think that the needle of an EAI will be located under the safety cap, but in some EAIs, the needle is located on the opposite end, which may cause users to hold the device upside down. ${ }^{62,63}$ Unfortunately, proper EAI administration technique is lacking at all levels. Among both food-allergic teenagers and parents of younger food-allergic children, only $38 \%$ were able to correctly demonstrate how to administer an EAI. ${ }^{35}$ The pharmacists who dispense EAIs are often tasked with instructing patients on the use of EAIs. However, 35\% of Australian pharmacists were unable to correctly demonstrate the most important steps in EAI administration, with $12 \%$ 


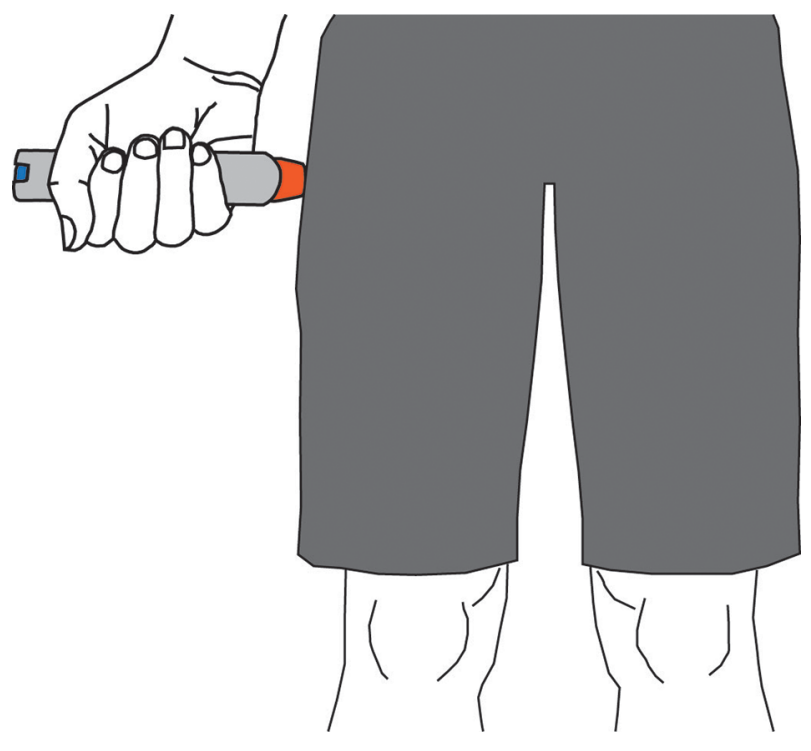

Figure 3 Self-administration of an epinephrine auto-injector.

incorrectly placing their thumb over the end of the device. ${ }^{64}$ Similarly, the majority of medical professionals in metropolitan Toronto did not hold an EAI correctly when demonstrating its use. ${ }^{61}$ A study on general pediatric physicians in Turkey showed that when asked to simulate the administration of an EAI with a trainer device, $36 \%$ of them used a technique that may have caused self-injection into their own thumb. ${ }^{65}$ However, after theoretical and practical training, the potential self-injection rate was reduced to $7 \%,{ }^{65}$ demonstrating the value of such training. Results from a study of interns with no prior EAI training demonstrated that EAI usage skills significantly decreased 6 months after initial training. ${ }^{66}$ Thus, it is important that regular retraining of all those who may need to administer an EAI be emphasized, especially for medical providers who train patients and caregivers on appropriate techniques. In addition, advances in EAI technology may help prevent accidental injections. While older EAIs had exposed needles, some modern EAIs, like the recently redesigned EpiPen Auto-Injector, have been modified to help prevent accidental injections. ${ }^{18,67}$ These modifications include an orange needle sheath and a "needle end" label with a prominent arrow indicating proper orientation (Figure 4). ${ }^{60}$ Together, improved training and further device enhancements may prove beneficial in the prevention of accidental injections.

\section{Laceration injuries}

Recent publications by Brown et al have raised concerns over laceration and embedded-needle injuries resulting from the use of EAIs. ${ }^{17,18}$ These studies used social media and e-mail discussion groups to identify cases of injuries resulting from EAI use that occurred in North America.
A

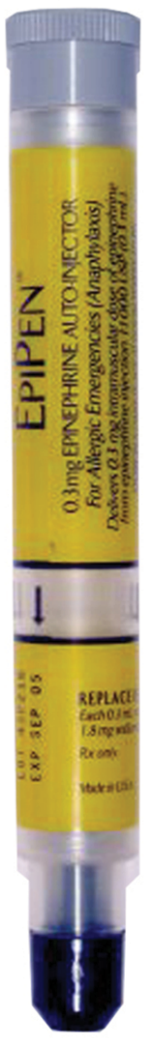

B

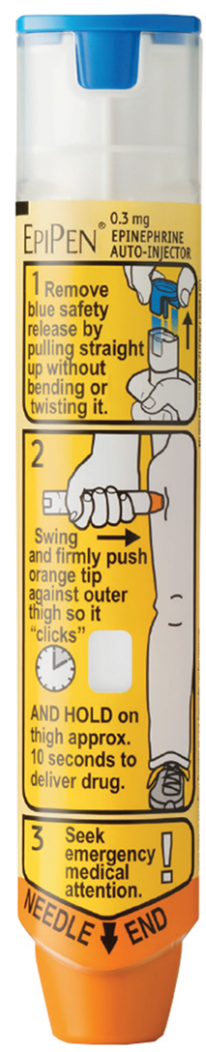

Figure 4 Comparison of the (A) old-look and (B) new-look (right) EpiPen ${ }^{\circledR}$ AutoInjector (Mylan Specialty L.P., Canonsburg, PA, USA).

Note: The EpiPen Auto-Injector was redesigned in 2011 to include safety features such as the orange needle sheath.

Together, they reported a total of 26 cases of laceration and embedded-needle injuries, 25 of which occurred when an adult was administering an EAI to a child under the age of $11 .{ }^{17,18}$ Of the reported incidents, only $12 \%$ required wound repair with sutures. ${ }^{17,18}$ Although images of such injuries may be startling, they are believed to be rare events, and the authors emphasized that they should not discourage the use of an EAI. ${ }^{18}$ However, these reports provide helpful insight into the steps caregivers can take to prevent laceration and embedded-needle injuries when administering an EAI.

The majority of reported laceration injuries are the result of a child moving or jerking while epinephrine is being administered. ${ }^{17,18}$ This demonstrates the importance of properly restraining a child while administering an EAI. Recent studies have emphasized the importance of restraint and immobilization techniques (Figure 5). ${ }^{17}$ In addition, the prescribing information for the EpiPen Auto-Injector was recently updated to recommend that the caregiver hold the child's leg firmly in place both before and during the injection. ${ }^{60}$ In order to help prevent laceration injuries, it may be important to identify the most effective methods of restraint and communicate these techniques to those who may have to administer an EAI to an uncooperative child. 


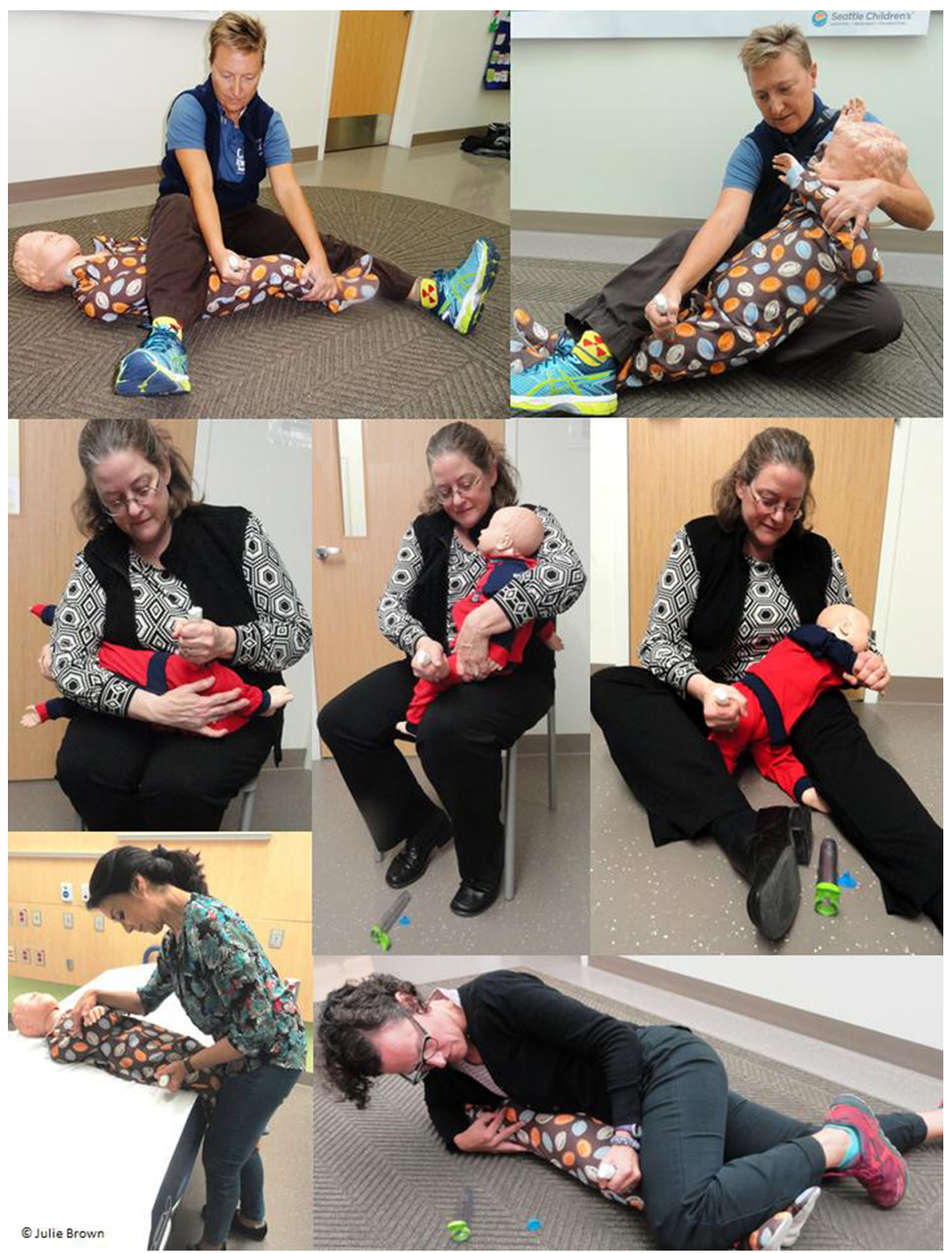

Figure 5 Proposed child restraint options for the administration of an epinephrine auto-injector.

Note: Reprinted from The Journal of Allergy and Clinical Immunology: In Practice, Volume 4/edition 3, Brown JC, Tuuri RE, Lacerations and embedded needles due to EpiPen use in children, Pages 549-55I, Copyright 2016, with permission from Elsevier and Julie Brown, MD, MPH. ${ }^{17}$

Some laceration injuries could also be the result of a physician or caregiver trying to reinsert the needle after a child jerked free. ${ }^{18}$ The EAIs available in North America have been prescribed with directions to insert the needle into the thigh and hold for $10 \mathrm{~s}$ to ensure full dose delivery. ${ }^{18}$ Very recently, the prescribing information for the EpiPen Auto-Injector was changed to shorten the time of insertion to $3 \mathrm{~s}$ and to massage the injection site for an additional $10 \mathrm{~s} .{ }^{60}$ Epinephrine absorption should not be affected by this recommendation, as suggested by a study that used EAIs to inject epinephrine into beef. ${ }^{68}$ This study indicated that there may not be an increase in epinephrine absorbed or dispensed past $1 \mathrm{~s}$ of injection. Thus, the new shortened injection time should improve the safety profile of EAIs, as laceration injuries have occurred after trying to reinsert a needle that has become dislodged in $<10$ s. $^{18}$ Another EAI that was formerly available had a needle that automatically retracted after injection to help prevent laceration injuries. ${ }^{18}$ However, the actual benefits of shortened injection time and retractable needles remain unclear. While laceration injuries may be uncommon, it was agreed that more research and discussion are required on how to further prevent them.

\section{Use of expired epinephrine}

Epinephrine is an unstable chemical. ${ }^{69,70}$ Accordingly, EAIs have a relatively short shelf-life, and prescribing 
information states that they should be stored at $20^{\circ} \mathrm{C}-25^{\circ} \mathrm{C}$ $\left(68^{\circ} \mathrm{F}-77^{\circ} \mathrm{F}\right) .{ }^{59,60}$ Once the expiration date has passed, the concentration and bioavailability of epinephrine in an EAI decrease over time. ${ }^{69,71}$ Similarly, epinephrine stored outside the recommended temperature range may not provide the labeled dose. ${ }^{72}$

Many patients carry expired EAIs, which may be the only source of epinephrine available. ${ }^{35}$ Recent literature suggests that physicians may give conflicting or inaccurate information regarding the safety and efficacy of expired EAIs. Some physicians highly emphasize the importance of keeping EAIs up to date. ${ }^{73}$ In contrast, some patients have reported that health care professionals have advised them to ignore the expiration dates and that EAIs are safe to use unless they are cloudy or discolored. ${ }^{19}$ However, significant degradation of epinephrine in an EAI can occur in the absence of discoloration or precipitation, indicating that appearance alone should not be used to determine whether an EAI is safe to use..$^{74}$ Other experts have suggested that if an expired EAI is the only source of epinephrine available to treat an anaphylactic event, it may be used as the risk of using a suboptimal dose of epinephrine potentially outweighs the risk of using no epinephrine at all. ${ }^{69}$ There are instances where patients have died from anaphylactic attacks after having been administered epinephrine from an expired EAI. ${ }^{75}$ Thus, in order to ensure proper treatment of anaphylaxis, it is believed that EAIs should always be replaced before they expire,,$^{2,69}$ and physicians should emphasize the importance of restocking expired EAIs to patients.

\section{Discussion}

Although epinephrine is an important, potentially life-saving, first-line therapy for anaphylaxis, concerns over safety may prevent someone from receiving timely epinephrine. One study revealed, for example, that a majority of parents of children with a peanut allergy and an epinephrine prescription are afraid of administering an EAI. ${ }^{10}$ Commonly cited concerns included hurting the child, using the EAI incorrectly, and a bad outcome or death. This demonstrates that even parents with some level of training on EAI usage may have lingering concerns that affect their confidence in their ability to safely administer an EAI.

Although important efforts are being made with legislative and policy changes to increase the availability of EAIs, ${ }^{42-46}$ these alone are not enough, as people also need to be willing and able to safely use them. Multiple reports show that parents who had previously administered an EAI were more comfortable with using an EAI than those who had not. ${ }^{10,76}$ This suggests that overall familiarity with an EAI makes a parent more comfortable and perhaps more likely to administer an EAI during an emergency. Thus, regular handson training, perhaps in conjunction with yearly prescription renewals (which include placebo trainer devices), may be the most beneficial for helping to prevent injuries associated with EAI use, such as accidental injections and lacerations.

Addressing potential knowledge gaps for medical providers is also important. Medical providers need to be able to properly administer epinephrine to prevent CV AEs associated with epinephrine overdose and to train patients on the proper use of EAIs ${ }^{61,65}$ and the importance of replacing their EAIs before they expire. ${ }^{73}$ While very basic training methods may be extremely beneficial in preventing epinephrineassociated injuries, ${ }^{47,65}$ recurring reminders on proper EAI use may also be valuable. ${ }^{66}$ There are legitimate safety concerns with the administration of EAIs, but recent evidence shows that injuries are rare and typically not serious. Moreover, there is a broad agreement that these safety concerns are far outweighed by the benefits of prompt administration of an EAI to treat anaphylaxis. ${ }^{5,13,18,69}$

\section{Acknowledgments}

Editorial assistance was provided under the direction of the authors by Scott Houck, PhD, and Jennifer Rossi, MA, ELS, MedThink SciCom, and funded by Mylan Specialty L.P.

\section{Disclosure}

Dr Posner has served on the scientific advisory board for Mylan Specialty L.P. and Dr Camargo for Mylan Specialty L.P. and Sanofi-Aventis. Dr Posner and Dr Camargo performed investigator-initiated research funded by Mylan Specialty L.P. The authors report no other conflicts of interest in this work.

\section{References}

1. Sampson HA, Muñoz-Furlong A, Campbell RL, et al. Second symposium on the definition and management of anaphylaxis: summary report-second National Institute of Allergy and Infectious Disease/Food Allergy and Anaphylaxis Network symposium. Ann Emerg Med. 2006; 47(4):373-380.

2. Simons FE, Ardusso LR, Bilò MB, et al. World allergy organization guidelines for the assessment and management of anaphylaxis. World Allergy Organ J. 2011;4(2):13-37.

3. Muraro A, Roberts G, Worm M, et al. Anaphylaxis: guidelines from the European Academy of Allergy and Clinical Immunology. Allergy. 2014;69(8):1026-1045.

4. Soar J, Pumphrey R, Cant A, et al. Emergency treatment of anaphylactic reactions - guidelines for healthcare providers. Resuscitation. 2008;77(2):157-169.

5. NIAID-Sponsored Expert Panel, Boyce JA, Assa'ad A, et al. Guidelines for the diagnosis and management of food allergy in the United States: report of the NIAID-sponsored expert panel. J Allergy Clin Immunol. 2010;126(6 Suppl):S1-S58. 
6. Ko BS, Kim JY, Seo DW, et al. Should adrenaline be used in patients with hemodynamically stable anaphylaxis? Incident case control study nested within a retrospective cohort study. Sci Rep. 2016;6:20168.

7. Bock SA, Muñoz-Furlong A, Sampson HA. Further fatalities caused by anaphylactic reactions to food, 2001-2006. JAllergy Clin Immunol. 2007;119(4):1016-1018.

8. Fleming JT, Clark S, Camargo CA Jr, Rudders SA. Early treatment of food-induced anaphylaxis with epinephrine is associated with a lower risk of hospitalization. JAllergy Clin Immunol Pract. 2015;3(1):57-62.

9. Simons FE, Clark S, Camargo CA Jr. Anaphylaxis in the community: learning from the survivors. J Allergy Clin Immunol. 2009;124(2): 301-306.

10. Chad L, Ben-Shoshan M, Asai Y, et al. A majority of parents of children with peanut allergy fear using the epinephrine auto-injector. Allergy. 2013;68(12):1605-1609.

11. Carter BT, Westfall VK, Heironimus TW, Atuk NO. Severe reaction to accidental subcutaneous administration of large doses of epinephrine. Anesth Analg. 1971;50(2):175-178.

12. Campbell RL, Bellolio MF, Knutson BD, et al. Epinephrine in anaphylaxis: higher risk of cardiovascular complications and overdose after administration of intravenous bolus epinephrine compared with intramuscular epinephrine. J Allergy Clin Immunol Pract. 2015;3(1): 76-80.

13. Wood JP, Traub SJ, Lipinski C. Safety of epinephrine for anaphylaxis in the emergency setting. World J Emerg Med. 2013;4(4):245-251.

14. Peyko V, Cohen V, Jellinek-Cohen SP, Pearl-Davis M. Evaluation and treatment of accidental autoinjection of epinephrine. Am J Health Syst Pharm. 2013;70(9):778-781.

15. Carrascosa MF, Gallastegui-Menéndez A, Teja-Santamaría C, Salcines Caviedes JR. Accidental finger ischaemia induced by epinephrine autoinjector. BMJ Case Rep. 2013;2013.

16. Bodkin RP, Acquisto NM, Gunyan H, Wiegand TJ. Two cases of accidental injection of epinephrine into a digit treated with subcutaneous phentolamine injections. Case Rep Emerg Med. 2013;2013:586207.

17. Brown JC, Tuuri RE. Lacerations and embedded needles due to EpiPen use in children. J Allergy Clin Immunol Pract. 2016;4(3): 549-551.

18. Brown JC, Tuuri RE, Akhter S, et al. Lacerations and embedded needles caused by epinephrine autoinjector use in children. Ann Emerg Med 2016;67(3):307-315.

19. Money AG, Barnett J, Kuljis J, Lucas J. Patient perceptions of epinephrine auto-injectors: exploring barriers to use. Scand J Caring Sci. 2013;27(2):335-344.

20. Huang F, Chawla K, Järvinen KM, Nowak-Węgrzyn A. Anaphylaxis in a New York City pediatric emergency department: triggers, treatments, and outcomes. J Allergy Clin Immunol. 2012;129(1):162-168.

21. Wood RA, Camargo CA Jr, Lieberman P, et al. Anaphylaxis in America: the prevalence and characteristics of anaphylaxis in the United States. J Allergy Clin Immunol. 2014;133(2):461-467.

22. White MV, Hogue SL, Bennett ME, et al. EpiPen4Schools pilot survey: occurrence of anaphylaxis, triggers, and epinephrine administration in a U.S. school setting. Allergy Asthma Proc. 2015;36(4):306-312.

23. Poulos LM, Waters AM, Correll PK, Loblay RH, Marks GB. Trends in hospitalizations for anaphylaxis, angioedema, and urticaria in Australia, 1993-1994 to 2004-2005. J Allergy Clin Immunol. 2007;120(4): $878-884$.

24. Rudders SA, Arias SA, Camargo CA Jr. Trends in hospitalizations for food-induced anaphylaxis in US children, 2000-2009. J Allergy Clin Immunol. 2014;134(4):960-962.

25. Branum AM, Lukacs SL. Food allergy among children in the United States. Pediatrics. 2009;124(6):1549-1555.

26. Webb LM, Lieberman P. Anaphylaxis: a review of 601 cases. Ann Allergy Asthma Immunol. 2006;97(1):39-43.

27. Pumphrey R. Anaphylaxis: can we tell who is at risk of a fatal reaction? Curr Opin Allergy Clin Immunol. 2004;4(4):285-290.

28. Lodish H, Berk A, Zipursky SL, Matsudaira P, Baltimore D, Darnell J. G protein-coupled receptors and their effectors. In: Molecular Cell Biology. 4th ed. New York: W.H. Freeman; 2000: Section 20.3.
29. Fineman SM. Optimal treatment of anaphylaxis: antihistamines versus epinephrine. Postgrad Med. 2014;126(4):73-81.

30. Fuzak JK, Trainor J. Comparison of the incidence, etiology, and management of anaphylaxis over time. Pediatr Emerg Care. 2013;29(2): 131-135.

31. Rudders SA, Banerji A, Corel B, Clark S, Camargo CA Jr. Multicenter study of repeat epinephrine treatments for food-related anaphylaxis. Pediatrics. 2010;125(4):e711-e718.

32. Simons FE. First-aid treatment of anaphylaxis to food: focus on epinephrine. J Allergy Clin Immunol. 2004;113(5):837-844.

33. Simons FE. Advances in $\mathrm{H}_{1}$-antihistamines. $N$ Engl J Med. 2004; 351(21):2203-2217.

34. Ku MS. Recent trends in specialty pharma business model. J Food Drug Anal. 2015;23(4):595-608.

35. Sicherer SH, Forman JA, Noone SA. Use assessment of self-administered epinephrine among food-allergic children and pediatricians. Pediatrics. 2000;105(2):359-362.

36. Clark S, Wei W, Rudders SA, Camargo CA Jr. Risk factors for severe anaphylaxis in patients receiving anaphylaxis treatment in US emergency departments and hospitals. J Allergy Clin Immunol. 2014; 134(5):1125-1130.

37. Jacobsen RC, Toy S, Bonham AJ, Salomone JA III, Ruthstrom J, Gratton M. Anaphylaxis knowledge among paramedics: results of a national survey. Prehosp Emerg Care. 2012;16(4):527-534.

38. Peterson DC, Martin-Gill C, Guyette FX, et al. Outcomes of medical emergencies on commercial airline flights. N Engl J Med. 2013;368(22): 2075-2083.

39. Nable JV, Tupe CL, Gehle BD, Brady WJ. In-flight medical emergencies during commercial travel. N Engl J Med. 2015;373(10):939-945.

40. Federal Aviation Administration, Department of Transportation. Emergency medical equipment. Final rule. Fed Regist. 2001;66(71): 19028-19046.

41. McIntyre CL, Sheetz AH, Carroll CR, Young MC. Administration of epinephrine for life-threatening allergic reactions in school settings. Pediatrics. 2005;116(5):1134-1140.

42. National Association of EMS Physicians. The Use of Epinephrine for Out-of-hospital Treatment of Anaphylaxis. Lenexa, KS: National Association of EMS Physicians; 2011.

43. Airline Access to Emergency Epinephrine Act of 2015, S 1972, 114th Cong, 1st Sess (2015)

44. US Public Law. School Access to Emergency Epinephrine Act. Pub L No. 113-48, 127; Statute 575. November 13, 2013.

45. Zadikoff EH, Whyte SA, DeSantiago-Cardenas L, Harvey-Gintoft B, Gupta RS. The development and implementation of the Chicago Public Schools emergency EpiPen ${ }^{\circledR}$ policy. J Sch Health. 2014;84(5):342-347.

46. The Network for Public Health Law. Summary Matrix of State Laws Addressing Epi-Pen Use in Schools. St Paul, MN: The Network for Public Health Law; 2015.

47. Kanwar M, Irvin CB, Frank JJ, Weber K, Rosman H. Confusion about epinephrine dosing leading to iatrogenic overdose: a life-threatening problem with a potential solution. Ann Emerg Med. 2010;55(4):341-344.

48. Rolfe S, Harper NJ. Ability of hospital doctors to calculate drug doses. BMJ. 1995;310(6988):1173-1174.

49. Paparella SF. Say goodbye to confusing ratio expressions. J Emerg Nurs. 2016;42(5):431-433.

50. McLean-Tooke AP, Bethune CA, Fay AC, Spickett GP. Adrenaline in the treatment of anaphylaxis: what is the evidence? BMJ. 2003;327(7427): 1332-1335.

51. Grossman SL, Baumann BM, Garcia Peña BM, Linares MY, Greenberg B, Hernandez-Trujillo VP. Anaphylaxis knowledge and practice preferences of pediatric emergency medicine physicians: a national survey. J Pediatr. 2013;163(3):841-846.

52. Sasaki K, Nakagawa T, Sugiura S, Kando N, Ito K. Accidental usage of an adrenaline auto-injector in Japanese children with a food allergy. Allergol Int. 2016;65(3):349-350.

53. Simons FE, Lieberman PL, Read EJ Jr, Edwards ES. Hazards of unintentional injection of epinephrine from autoinjectors: a systematic review. Ann Allergy Asthma Immunol. 2009;102(4):282-287. 
54. Simons FE, Edwards ES, Read EJ Jr, Clark S, Liebelt EL. Voluntarily reported unintentional injections from epinephrine auto-injectors. J Allergy Clin Immunol. 2010;125(2):419-423.

55. Fitzcharles-Bowe C, Denkler K, Lalonde D. Finger injection with highdose $(1: 1,000)$ epinephrine: does it cause finger necrosis and should it be treated? Hand (NY). 2007;2(1):5-11.

56. Muck AE, Bebarta VS, Borys DJ, Morgan DL. Six years of epinephrine digital injections: absence of significant local or systemic effects. Ann Emerg Med. 2010;56(3):270-274.

57. Wright M. Treatment after accidental injection with epinephrine autoinjector: a systematic review. J Allergy Ther. 2014;5(3):175.

58. Azzi M. Mother reveals the heartbreaking story of how her son died at school due to his peanut allergy despite it's 'nut-free policy' - and how the teacher stabbed the EpiPen into her own hand instead of little Alex. Daily Mail. 2015 Sep 2. Available from: http://www.dailymail.co.uk/ news/article-3219624/Mother-reveals-heartbreaking-moment-calledson-s-kindergarten-told-died-peanut-allergy-despite-school-nut-free. html. Accessed March 8, 2016.

59. Adrenaclick $®$ (epinephrine injection USP) auto-injector [package insert]. Horsham, PA: Amedra Pharmaceuticals LLC; 2013.

60. EpiPen ${ }^{\circledR}$ (epinephrine injection) Auto-Injector [package insert]. Morgantown, WV: Mylan Specialty L.P.; 2016.

61. Grouhi M, Alshehri M, Hummel D, Roifman CM. Anaphylaxis and epinephrine auto-injector training: who will teach the teachers? J Allergy Clin Immunol. 1999;104(1):190-193.

62. Lee J. The role of metaphor in design: impact on health outcomes. Medium. Available from: https://medium.com/@joyclee/the-role-of-metaphor-indesign-cd6d8f04daab\#.yb0oqje6z. Accessed December 5, 2016.

63. Frew AJ. What are the 'ideal' features of an adrenaline (epinephrine) auto-injector in the treatment of anaphylaxis? Allergy. 2011;66(1): $15-24$.

64. Salter SM, Loh R, Sanfilippo FM, Clifford RM. Demonstration of epinephrine autoinjectors (EpiPen and Anapen) by pharmacists in a randomised, simulated patient assessment: acceptable, but room for improvement. Allergy Asthma Clin Immunol. 2014;10(1):49.
65. Arga M, Bakirtas A, Catal F, et al. Training of trainers on epinephrine autoinjector use. Pediatr Allergy Immunol. 2011;22(6):590-593.

66. Topal E, Bakirtas A, Yilmaz O, Karagol IH, Arga M, Demirsoy MS, Turktas I. When should we perform a repeat training on adrenaline auto-injector use for physician trainees? Allergol Immunopathol (Madr). 2014;42(5):472-475.

67. Guerlain S, Wang L, Hugine A. Intelliject's novel epinephrine autoinjector: sharps injury prevention validation and comparable analysis with EpiPen and Twinject. Ann Allergy Asthma Immunol. 2010;105(6): 480-484.

68. Baker TW, Webber CM, Stolfi A, Gonzalez-Reyes E. The TEN study: time epinephrine needs to reach muscle. Ann Allergy Asthma Immunol. 2011;107(3):235-238.

69. Simons FE, Gu X, Simons KJ. Outdated EpiPen and EpiPen Jr autoinjectors: past their prime? JAllergy Clin Immunol. 2000;105(5):1025-1030.

70. Church WH, Hu SS, Henry AJ. Thermal degradation of injectable epinephrine. Am J Emerg Med. 1994;12(3):306-309.

71. Rachid O, Simons FE, Wein MB, Rawas-Qalaji M, Simons KJ. Epinephrine doses contained in outdated epinephrine auto-injectors collected in a Florida allergy practice. Ann Allergy Asthma Immunol. 2015;114(4):354-356.

72. Rachid O, Simons FE, Rawas-Qalaji M, Lewis S, Simons KJ. Epinephrine doses delivered from auto-injectors stored at excessively high temperatures. Drug Dev Ind Pharm. 2016;42:131-135.

73. Bennett JR, Fromer L, Hayden ML. Anaphylaxis challenges on the front line: perspectives from community medicine. Am J Med. 2014;127(1 Suppl):S25-S33.

74. Parish HG, Bowser CS, Morton JR, Brown JC. A systematic review of epinephrine degradation with exposure to excessive heat or cold. Ann Allergy Asthma Immunol. 2016;117(1):79-87.

75. Pumphrey RS, Gowland $\mathrm{MH}$. Further fatal allergic reactions to food in the United Kingdom, 1999-2006. J Allergy Clin Immunol. 2007;119(4):1018-1019.

76. Kim JS, Sinacore JM, Pongracic JA. Parental use of EpiPen for children with food allergies. J Allergy Clin Immunol. 2005;116(1):164-168.
Drug, Healthcare and Patient Safety

\section{Publish your work in this journal}

Drug, Healthcare and Patient Safety is an international, peer-reviewed open access journal exploring patient safety issues in the healthcare continuum from diagnostic and screening interventions through to treatment, drug therapy and surgery. The journal is characterized by the rapid reporting of reviews, original research, clinical, epidemiological and

\section{Dovepress}

post-marketing surveillance studies, risk management, health literacy and educational programs across all areas of healthcare delivery. The manuscript management system is completely online and includes a very quick and fair peer-review system. Visit http://www.dovepress.com/ testimonials.php to read real quotes from published authors. 